\title{
A Short-Term Prospective Study of Retroperitoneal Tumours in a Tertiary Hospital in Eastern India
}

\author{
Saurabh Das ${ }^{1}$, Arindam Das², Priya Ranjan Mandal ${ }^{3}$ \\ ${ }^{1}$ Department of General Surgery, IPGME\&R, Kolkata, West Bengal, India. ${ }^{2}$ Department of General Surgery, IPGME\&R, \\ Kolkata, West Bengal, India. ${ }^{3}$ Department of General Surgery, IPGME\&R, Kolkata, West Bengal, India.
}

\section{ABSTRACT}

\section{BACKGROUND}

Retroperitoneal tumours are rare but diverse group of neoplasms that arise from the retroperitoneum, and account for $10 \%$ of all soft tissue tumours. Managing retroperitoneal tumours is challenging because they typically present at a relatively late stage, and are anatomically proximate to major vessels and vital organs. This study was carried out to find out different clinicopathological profiles of patients who presented with retroperitoneal tumours in our hospital during the tenure of this study.

\section{METHODS}

This is an observational study. 25 patients with retroperitoneal tumours were studied. For statistical analysis, data was entered into a Microsoft Excel spreadsheet and then analysed with SPSS Version 25.0.

\section{RESULTS}

In our study, we studied 25 patients with retroperitoneal tumours. Most of the patients were in the age group of 40-60 years (48.00\%) with a mean age of 42 years and standard deviation of 15.0416. The most common presenting complaint (s) in the patient population attending our institution was abdominal lump and pain $(40.00 \%)$ followed by pain (32\%). Amongst the signs, $96 \%$ of the patients had an abdominal lump and $92 \%$ had tenderness. Transabdominal ultrasonography revealed 16 homogeneous and 9 heterogeneous masses for which computed tomography (CT Scan W/A) was done for all 25 patients studied which depicted 19 homogeneous (solid or cystic) and 6 mixed primary retroperitoneal tumours. All patients underwent open surgery at our institute, but complete resection was possible in only $18(72.00 \%)$ patients whereas $4(16.00 \%)$ underwent a partial resection and 3 patients were inoperable. 17 cases are reported to be malignant $(68.00 \%)$ with complete curative resection with margins free of tumour in $52.94 \%$ of them and 8 cases were benign (32.00\%) and all of them were found to have clear margins. Among the malignant tumours, liposarcomas were the most common while neural tissue tumours were the most common benign type.

\section{CONCLUSIONS}

The incidence of retroperitoneal tumours is maximum in the $5^{\text {th }}$ decade of life, though it can occur in any age group. Symptoms of pain abdomen, abdominal lump should be properly evaluated to diagnose retroperitoneal tumours.

\section{KEY WORDS}

Primary Retroperitoneal Tumour, Clinicopathological Profile
Corresponding Author:

Dr. Arindam Das,

18A, Santosh Roy Road,

Barisha, Kolkata-700008,

West Bengal, India.

E-mail: dasarindam1988@gmail.com

DOI: $10.14260 / j e m d s / 2020 / 101$

Financial or Other Competing Interests: None.

How to Cite This Article:

Das S, Das A, Mandal PR. A short- term prospective study of retroperitoneal tumours in a tertiary hospital in Eastern India. J. Evolution Med. Dent. Sci. 2020;9 (07):448-452, DOI: $10.14260 /$ jemds $/ 2020 / 101$

Submission 14-12-2019, Peer Review 23-01-2020,

Acceptance 29-01-2020,

Published 17-02-2020. 


\section{BACKGROUND}

Retroperitoneal tumour are rare but diverse group of neoplasms that arise from the retroperitoneum, comprising about $10 \%$ of all soft tissue tumours. ${ }^{1}$ Retroperitoneal tumours (RTs) commonly present with abdominal distension and palpable mass. In many cases, they are detected as a result of imaging techniques performed to investigate unrelated issues. Although Retroperitoneal tumours can be located in the gastrointestinal and urinary tracts, patients rarely present with symptoms in these systems. ${ }^{2,3}$ The retroperitoneal space is the second most frequent location, followed by the lower extremities, where malignant mesenchymal tumours arise. Each year, approximately 250 to 300 new cases of retroperitoneal sarcoma are diagnosed in the United Kingdom. ${ }^{4}$ Despite the rare nature of RTs, two thirds of these diagnoses represent malignant tumours. Managing retroperitoneal tumours is challenging because they typically present at a relatively late stage, and are anatomically proximate to major vessels and vital organs. Masses encountered in the retroperitoneum may be benign, primary malignant, or metastatic.

Primary retroperitoneal tumours presents an uncommon group of neoplasms that account for $0.01 \%$ to $0.3 \%$ of all tumours. $^{5-8}$ They derive from tissues contained in the retroperitoneal space (adipose, muscular, vessel and nerve tissue),from embryonic remnants or heterotopies coming from one or more embryonic layers (ectoderm, mesoderm and endoderm) or from totipotent embryonic germ cells. They do not include any growing lesions belonging to the retroperitoneal organs (kidneys, adrenal glands, excretory tract, pancreas and colon) or secondary invasive organs such as systemic masses (lymphomas) and metastases.9,10 The tumours are mostly malignant in both adults and infants $(62 \%-86 \%) \cdot{ }^{11,10,12-15}$

This short-term study was carried out to find out different clinicopathological profile of patients who presented with retroperitoneal tumours and this study was an effort to focus about characteristics of retroperitoneal tumours in our locality in eastern India.

\section{METHODS}

After taking approval from the institutional ethics committee, the study was carried out in the Department of General Surgery, SSKM Hospital, Kolkata. All cases with uncomplicated retroperitoneal tumours attending the study area within the mentioned time were included. Paediatric patients, unwilling patients and patients with tumours arising from the kidney and pancreas were excluded. A total of 25 patients was considered. (SINCE these are rare tumours, only patients meeting the inclusion and exclusion criteria within the study time were considered) Patients meeting the inclusion and exclusion criteria were subjected to a detailed history and clinical examination, investigations (including ultrasonography, contrast enhanced CT-Scan of the abdomen, routine blood tests) and prepared for surgery. Preoperatively, the resectability was assessed. If resectable, the mass was resected. If complete resection was not feasible, a debulking partial resection was carried out. If unresectable, some tissue was taken for histopathological examination. The preoperative radiological findings were tallied with the preoperative findings. Postoperatively, the histopathological characteristics were studied.

\section{Statistical Analysis}

For statistical analysis data were entered into a Microsoft excel spreadsheet and then analyzed by SPSS (version 25.0; SPSS Inc., Chicago, IL, USA). Data had been summarized as mean and standard deviation for numerical variables and count and percentages for categorical variables. A chisquared test ( $\chi^{2}$ test) was any statistical hypothesis test wherein the sampling distribution of the test statistic is a chisquared distribution when the null hypothesis is true. Without other qualification, 'chi-squared test' often is used as short for Pearson's chi-squared test. Unpaired proportions were compared by Chi-square test or Fischer's exact test, as appropriate. $\mathrm{p}$-value $\leq 0.05$ was considered for statistically significant.

\section{RESULTS}

\begin{tabular}{|c|c|c|c|c|c|}
\hline & & Frequency & Percent & Z-value & p-value \\
\hline \multirow{7}{*}{ Age in years } & $12-20$ & 4 & $16.0 \%$ & \multirow{7}{*}{0.6623} & \multirow{7}{*}{.50926} \\
\hline & $21-30$ & 2 & $8.0 \%$ & & \\
\hline & $31-40$ & 4 & $16.0 \%$ & & \\
\hline & $41-50$ & 7 & $28.0 \%$ & & \\
\hline & $51-60$ & 5 & $20.0 \%$ & & \\
\hline & $61-70$ & 3 & $12.0 \%$ & & \\
\hline & Total & 25 & $100.0 \%$ & & \\
\hline \multirow{3}{*}{ Sex } & Female & 13 & $52.0 \%$ & \multirow{3}{*}{0.2828} & \multirow{3}{*}{.77948} \\
\hline & Male & 12 & $48.0 \%$ & & \\
\hline & Total & 25 & $100.0 \%$ & & \\
\hline \multicolumn{6}{|c|}{ Table 1 Age and Sex Distribution } \\
\hline
\end{tabular}

\begin{tabular}{|c|c|c|c|c|c|}
\hline & & Frequency & $\%$ & Z-value & p \\
\hline \multirow{4}{*}{ Chief complaints } & Abdominal lump & 7 & $28.0 \%$ & \multirow{4}{*}{0.5893} & \multirow{4}{*}{.5552} \\
\hline & Abdominal lump + pain & 10 & $40.0 \%$ & & \\
\hline & Pain & 8 & $32.0 \%$ & & \\
\hline & Total & 25 & $100.0 \%$ & & \\
\hline \multirow{3}{*}{ Lump } & No & 1 & $4.0 \%$ & \multirow{3}{*}{6.5054} & \multirow{3}{*}{$<.00001$} \\
\hline & Yes & 24 & $96.0 \%$ & & \\
\hline & Total & 25 & $100.0 \%$ & & \\
\hline \multirow{3}{*}{ Tenderness } & No & 2 & $8.0 \%$ & \multirow{3}{*}{5.9397} & \multirow{3}{*}{$<.00001$} \\
\hline & Yes & 23 & $92.0 \%$ & & \\
\hline & Total & 25 & $100.0 \%$ & & \\
\hline
\end{tabular}

Table 2. Distribution of Chief Complaints, Lump and Tenderness

\begin{tabular}{|c|c|c|c|c|c|}
\hline & & Frequency & $\%$ & $\begin{array}{c}\text { Z- } \\
\text { value }\end{array}$ & $\mathbf{p}$ \\
\hline \multirow{2}{*}{ Ascites-USG } & No & 19 & $76.0 \%$ & \multirow{2}{*}{3.677} & \multirow{2}{*}{.00024} \\
\hline & Yes & 6 & $24.0 \%$ & & \\
\hline \multirow{2}{*}{$\begin{array}{c}\text { Displacing bowel } \\
\text { loops-USG }\end{array}$} & No & 5 & $20.0 \%$ & \multirow{2}{*}{4.2426} & \multirow{2}{*}{$<.00001$} \\
\hline & Yes & 20 & $80.0 \%$ & & \\
\hline \multirow{2}{*}{ Composition USG } & Heterogeneous & 9 & $36.0 \%$ & \multirow{2}{*}{1.9799} & \multirow{2}{*}{.0477} \\
\hline & Homogeneous & 16 & $64.0 \%$ & & \\
\hline \multirow{2}{*}{ USG Boundary } & Ill Defined & 14 & $56.0 \%$ & \multirow{2}{*}{0.8485} & \multirow{2}{*}{.39532} \\
\hline & Well Defined & 11 & $44.0 \%$ & & \\
\hline \multirow{2}{*}{$\begin{array}{l}\text { Invading adjacent } \\
\text { structures-CT scan }\end{array}$} & No & 15 & $60.0 \%$ & \multirow{2}{*}{1.4142} & \multirow{2}{*}{.15854} \\
\hline & Yes & 10 & $40.0 \%$ & & \\
\hline \multirow{2}{*}{ Fat planes-CT scan } & Lost & 15 & $60.0 \%$ & \multirow{2}{*}{1.4142} & \multirow{2}{*}{.15854} \\
\hline & Preserved & 10 & $40.0 \%$ & & \\
\hline \multirow{2}{*}{ Composition CT scan } & Heterogeneous & 6 & $24.0 \%$ & \multirow{2}{*}{3.677} & \multirow{2}{*}{.00024} \\
\hline & Homogeneous & 19 & $76.0 \%$ & & \\
\hline \multirow{2}{*}{ CTScan Boundary } & Ill Defined & 14 & $56.0 \%$ & \multirow{2}{*}{0.8485} & \multirow{2}{*}{.39532} \\
\hline & Well Defined & 11 & $44.0 \%$ & & \\
\hline \multirow{3}{*}{ Type of resection } & Complete resection & 18 & $72.0 \%$ & \multirow{3}{*}{3.9886} & \multirow{3}{*}{.00006} \\
\hline & Partial & 4 & $16.0 \%$ & & \\
\hline & Unresectable & 3 & $12.0 \%$ & & \\
\hline \multirow{5}{*}{ Histopathology } & Cystic inflammatory mass & 1 & $4.0 \%$ & \multirow{5}{*}{1.9868} & \multirow{5}{*}{.0466} \\
\hline & Ganglioneuroma & 1 & $4.0 \%$ & & \\
\hline & Leiomyosarcoma & 1 & $4.0 \%$ & & \\
\hline & Lipoma & 1 & $4.0 \%$ & & \\
\hline & Liposarcoma & 9 & $36.0 \%$ & & \\
\hline
\end{tabular}




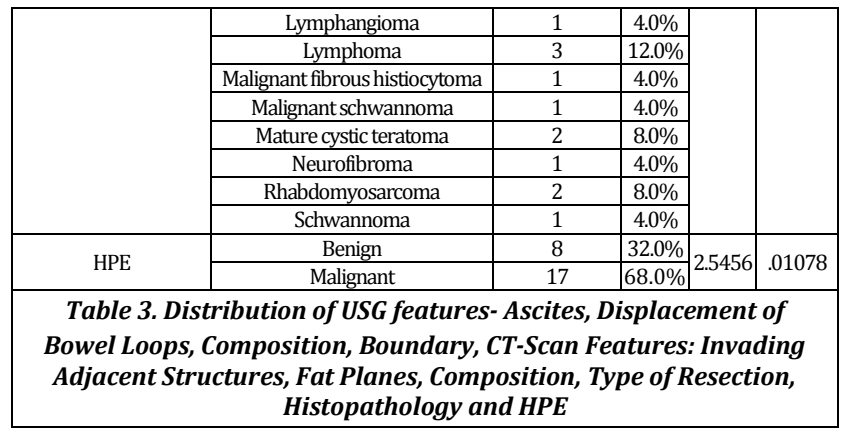

\begin{tabular}{|c|c|c|c|}
\hline \multicolumn{4}{|c|}{ HPE } \\
\hline Histopathology & Benign & Malignant & Total \\
\hline Cystic inflammatory mass & 1 & 0 & 1 \\
\hline Row \% & 100.0 & 0.0 & 100.0 \\
\hline Col \% & 12.5 & 0.0 & 4.0 \\
\hline Ganglioneuroma & 1 & 0 & 1 \\
\hline Row \% & 100.0 & 0.0 & 100.0 \\
\hline Col \% & 12.5 & 0.0 & 4.0 \\
\hline Leiomyosarcoma & 0 & 1 & 1 \\
\hline Row $\%$ & 0.0 & 100.0 & 100.0 \\
\hline Col \% & 0.0 & 5.9 & 4.0 \\
\hline Lipoma & 1 & 0 & 1 \\
\hline Row \% & 100.0 & 0.0 & 100.0 \\
\hline Col \% & 12.5 & 0.0 & 4.0 \\
\hline Liposarcoma & 0 & 9 & 9 \\
\hline Row \% & 0.0 & 100.0 & 100.0 \\
\hline Col \% & 0.0 & 52.9 & 36.0 \\
\hline Lymphangioma & 1 & 0 & 1 \\
\hline Row \% & 100.0 & 0.0 & 100.0 \\
\hline $\mathrm{Col} \%$ & 12.5 & 0.0 & 4.0 \\
\hline Lymphoma & 0 & 3 & 3 \\
\hline Row \% & 0.0 & 100.0 & 100.0 \\
\hline Col \% & 0.0 & 17.6 & 12.0 \\
\hline Malignant fibrous histiocytoma & 0 & 1 & 1 \\
\hline Row $\%$ & 0.0 & 100.0 & 100.0 \\
\hline Col \% & 0.0 & 5.9 & 4.0 \\
\hline Malignant schwannoma & 0 & 1 & 1 \\
\hline Row \% & 0.0 & 100.0 & 100.0 \\
\hline $\mathrm{Col} \%$ & 0.0 & 5.9 & 4.0 \\
\hline Mature cystic teratoma & 2 & 0 & 2 \\
\hline Row \% & 100.0 & 0.0 & 100.0 \\
\hline Col \% & 25.0 & 0.0 & 8.0 \\
\hline Neurofibroma & 1 & 0 & 1 \\
\hline Row \% & 100.0 & 0.0 & 100.0 \\
\hline Col \% & 12.5 & 0.0 & 4.0 \\
\hline Rhabdomyosarcoma & 0 & 2 & 2 \\
\hline Row \% & 0.0 & 100.0 & 100.0 \\
\hline $\mathrm{Col} \%$ & 0.0 & 11.8 & 8.0 \\
\hline Schwannoma & 1 & 0 & 1 \\
\hline Row \% & 100.0 & 0.0 & 100.0 \\
\hline $\mathrm{Col} \%$ & 12.5 & 0.0 & 4.0 \\
\hline TOTAL & 8 & 17 & 25 \\
\hline Row \% & 32.0 & 68.0 & 100.0 \\
\hline Col \% & 100.0 & 100.0 & 100.0 \\
\hline Table 4. Hist & ology: & & \\
\hline
\end{tabular}

\section{DISCUSSION}

The current study was an endeavour to assess the clinicopathological characteristics of primary retroperitoneal tumours in adult population at a Tertiary Referral Hospital in Eastern India. As they are rare tumours, our study comprised of 25 patients assessed over a period of January 2016September 2017. Most of the patients were in the age group of $40-60$ years $(48.00 \%)$ with a mean age of 42 years and standard deviation of 15.0416 . This corroborates with the study of CE Gratita et $\mathrm{al}^{16}$ who also found that the incidence of these tumours is maximum in the fifth decade of life. 4 (16.0\%) patients had $12-20$ years of age, $2(8.0 \%)$ patients had 21-30 years of age, 4 (16.0\%) patients had 31-40 years of age, $7(28.0 \%)$ patients had $41-50$ years of age, $5(20.0 \%)$ patients had 51-60 years of age and $3(12.0 \%)$ patients had 61-70 years of age. Distribution of age in years was not statistically significant ( $\mathrm{p}=.50926) .13(52.0 \%)$ patients had female and 12 (48.0\%) patients had male. Distribution of sex was not statistically significant ( $\mathrm{p}=.77948)$.

Most patients who have a retroperitoneal tumour present with abdominal swelling/increase in girth, early satiety and abdominal discomfort, and most patients have a palpable mass. ${ }^{3}$ Many benign lesions are discovered as an incidental finding during imaging for unrelated symptoms. ${ }^{2}$ Location of retroperitoneal mass will directly impact how the patient clinically presents. For example, retroperitoneal masses located near the kidney and ureters can cause a patient to present with decreased urinary output, flank pain, and renal failure. A retroperitoneal mass near the duodenum can manifest with gastric outlet obstruction leading to nausea, vomiting, and early satiety in patients. Occasionally, patients also experience nonspecific symptoms including vague abdominal pain, weight loss, general malaise, and nausea. Although the gastrointestinal and urinary tracts are often displaced, they are rarely invaded and gastrointestinal or urinary symptoms are unusual ${ }^{17}$, a high index of suspicion is needed in order to include retroperitoneal masses as a part of the differential diagnoses of common complaints such as nausea and abdominal pain.

Clinical symptoms are (in decreasing order of occurrence $)^{18}$ are abdominal/flank mass, pain, anaemia, upper urinary track obstructive symptoms, weight loss/anorexia, fever, intestinal obstructive symptoms, pedal oedema and haematuria. The most common presenting complaint (s) in the patient population attending our institution was abdominal lump and pain (40.00\%) followed by pain (32\%), abdominal lump (32\%). Amongst the signs, $96 \%$ of the patients had an abdominal lump and $92 \%$ had tenderness. Apart from these, majority of our patients complained of weight loss and/or anorexia. Ultrasonography is a good modality to differentiate solid from cystic mass. It can comment about the location. The investigation of choice is cross sectional imaging. Cross-sectional imaging has revolutionised the investigation of patients with retroperitoneal neoplasms. Both CT and MRI play an integral role in the characterisation of these masses and in evaluation of their extent and involvement of adjacent structures, and therefore in treatment planning. In order to define a primary retroperitoneal tumour as such, it is absolutely necessary to exclude its origin from retroperitoneal organs. ${ }^{19}$

Patients included in our study underwent transabdominal ultrasonography to reveal 16 homogenous and 9 heterogenous masses; which computed tomography (CT SCAN W/A) was done for all 25 patients studied which depicted 19 homogeneous (SOLID or cystic), 6 mixed primary retroperitoneal tumours; with invasion of adjacent structures by $10(40.00 \%)$, loss of fat planes in 15 cases $(60.00 \%)$ and encasement of vital vascular structures by 4 of them. Surgical exploration was carried out in all patients. Laparotomy was done in all of these. Prior to operative intervention, 4 patients underwent blood transfusion to correct their severe anaemia $(14.28 \%)$ which matches with S. Aliyu et $\mathrm{al}^{5}$ who also gave blood transfusion to 21 of their 130 patients (16.15\%) for the same preoperative complication of severe anaemia. Complete surgical resection is the only potential curative treatment modality for both benign and malignant retroperitoneal tumours, but, local recurrence in case of malignant tumours occurs in a large proportion of patients and is responsible for 
as many as $75 \%$ of tumour-related deaths. The prognostic factors that are known to govern local recurrence and overall survival in retroperitoneal tumours are complete macroscopic excision, tumour grade, multifocality and histological subtype. ${ }^{20,17}$ Within the framework of a study evaluating 500 patients with retroperitoneal sarcoma, who were treated at Memorial Sloan-Kettering Cancer Center, it was found that the average life expectancy for patients who had complete resection was 103 months, this decreased to 18 months for patients who had incomplete resection or whose tumours were inoperable. ${ }^{21}$

With the aim of curative resection and wide margins of excision in mind, the 22 patients underwent open surgery at our institute, but this was possible in only $18(72.00 \%)$ patients whereas $4(16.00 \%)$ underwent a partial resection and 3 were unresectable; which is in contrast to S. Aliyu et al $^{18}$ wherein complete tumour resection was achieved in $51.54 \%$ patients $(67 / 130)$ while 63 of the 130 patients (48.46\%) had either debulking or biopsy due to advanced disease. As per literature, during surgery for retroperitoneal sarcomas, resection of adjacent involved organs is frequently required and rates of resection of adjacent viscera are reported in large series from $34 \%$ to $93 \%$ while macroscopic clearance was obtained in $55-93 \% .22,23,24$ The most common organs requiring resection are the colon, kidney, pancreas and spleen. However, in our study, 1 patient required a right hemicolectomy followed by ileo-transverse anastomosis, 1 required a distal pancreatectomy and splenectomy, 1 required only splenectomy and 1 a nephrectomy. Thus, of the 18 cases undergoing complete resection, 4 required resection of adjacent organs (i.e. $22.22 \%$ ). The size of the tumours that were resected ranged from $10-45 \mathrm{~cm}$ in greatest dimensions, which is in sharp contrast to that of Jiang YY et al ${ }^{11}$ who reported a size variation of 3 to $34 \mathrm{~cm}$. This is significantly lower than our finding and the possible explanation for this is that in the Indian scenario patients present late, due to ignorance, neglect of personal health and lack of adequate health care facilities throughout the country, apart from other social factors. The total of 25 patients were then monitored post operatively and among them, 2 expired soon after the operation while 5 developed significant post-operative complications/morbidity.

The histopathological report was available for all our patients, and the broad categorization into benign and malignant was made, apart from the exact diagnosis. 17 cases are reported to be malignant $(68.00 \%)$ with complete curative resection and margins free of tumour in $52.94 \%$ of them. Similarly, 8 cases were benign (32.00\%) and all of them were found to have clear margins; these are unlike the findings of Li S25 who, in his study of 201 patients found 113 to be malignant $(56 \%)$ and complete resection of $51 \%$ of these; whereas $88(44 \%)$ tumours were benign with again a significant $81 \%$ of these undergoing complete curative resection. Among the malignant tumours, liposarcomas were the most common while neural tissue tumours were the most common in the benign group.

\section{CONCLUSIONS}

Although the incidence of retroperitoneal tumours is maximum in the $5^{\text {th }}$ decade of life, they can occur in any age group. Symptoms of pain abdomen, abdominal lump should be properly evaluated. It is recommended that retroperitoneal tumours be treated by an experienced team of surgeons, employing a multidisciplinary approach. Since these are rare conditions, more studies are needed for improving the outcome.

\section{REFERENCES}

[1] Kotilingam D, Lev DC, Lazar AJF, et al. Staging soft tissue sarcoma: evolution and change. CA Cancer J Clin 2006;56 (5):282-91; quiz 314-5.

[2] Hughes MJ, Thomas JM, Fisher C, et al. Imaging features of retroperitoneal and pelvic schwannomas. Clin Radiol 2005;60 (8):886-93.

[3] Hueman MT, Herman JM, Ahuja N. Management of retroperitoneal sarcomas. Surg Clin North Am 2008;88 (3):583-97, vii.

[4] Weiss SW, Goldblum JR. Enzinger and Weiss's Soft tissue tumours. $4^{\text {th }}$ edn. St. Louis: Mosby 2001.

[5] D'Amico DF, Frego M. I tumouri retroperitoneali. In: Collana monografica della Società Italiana di Chirurgia edn. Vol. 2. Rome: 1994: p. 20-34.

[6] Ebbe M. A $6 \mathrm{~kg}$ retroperitoneal liposarcoma in a 42year-old woman. Case Report. Scand J Urol Nephrol 1993;27 (3):409-12.

[7] Storm FK, Sondak V, Economou JS. Sarcomas of the retroperitoneum. In: Eilber FR, edr. The soft tissue sarcomas. Orlando: Grune \& Stratton Publisher 1987: p. 239-47.

[8] Tramontano R, Ponzio S, Fraccalini M, et al. Retroperitoneal tumours. Observations on 8 cases. Minerva Chir 1998;53 (6):539-41.

[9] Serio G, Danieli D, Procacci C, et al. Retroperitoneal tumours. Tactics, technics and surgical results. Chir Ital 1983;35 (1):3-37.

[10] Nishino $M$, Hayakawa K, Minami $M$, et al. Primary retroperitoneal neoplasms: CT and MR imaging findings with anatomic and pathologic diagnostic clues. Radiographics 2003;23 (1):45-57.

[11] Jiang YY. Primary retroperitoneal tumour. Zhonghua Zhong Liu Za Zhi [Chinese Journal of Oncology] 1986;8 (3):201-2.

[12] Engelken JD, Ros PR. Retroperitoneal MR imaging. Magn Reson Imaging Clin North Am 1997;5 (1):165-78.

[13] Heslin MJ, Smith JK. Imaging of soft tissue sarcomas. Surg Oncol Clin North Am 1999;8:91-107.

[14] Bautista N, Su W, O'Connell TX. Retroperitoneal soft tissue sarcomas: prognosis and treatment of primary and recurrent disease. Am Surg 2000;66 (9):832-6.

[15] Jaques DP, Coit DG, Brennan MF. Soft tissue sarcomas of the retroperitoneum. In: Shiu MH, Brennan MF, eds. Surgical management of soft tissue sarcoma. Philadelphhia: Lea \& Febiger 1989;12:157-69.

[16] Gâtiţă CE, Georgescu I, Nemeş R. Difficulties in diagnosis of primitive retroperitoneal tumours. Current Health Sciences Journal 2010;36 (3):132-5.

[17] Neuhaus SJ, Barry P, Clark MA, et al. Surgical management of primary and recurrent retroperitoneal liposarcoma. Br J Surg 2005;92 (2):246-52. 
[18] Aliyu S, Ibrahim AG, Mohammed BS, et al. Retroperitoneal tumours a ten year experience in University of Maiduguri Teaching Hospital North Eastern Nigeria. Int J Sci \& Res Pub 2015;5 (3):1-3.

[19] Pistolesi GF, Procacci C, Caudana R, et al. CT criteria of the differential diagnosis in primary retroperitoneal masses. Eur J Radiol 1984;4 (2):127-38.

[20] Strauss DC, Hayes AJ, Thway K, et al. Surgical management of primary retroperitoneal sarcoma. $\mathrm{Br}$ J Surg 2010;97 (5):698-706.

[21] Kattan MW, Leung DHY, Brennan MF. Postoperative nomogram for 12-year sarcoma-specific death. J Clin Oncol 2002;20 (3):791-6.

[22] Lewis JJ, Leung D, Woodruff JM, et al. Retroperitoneal soft-tissue sarcoma: analysis of 500 patients treated and followed at a single institution. Ann Surg 1998;228 (3):355-65.
[23] Bonvalot S, Rivoire M, Castaing M, et al. Primary retroperitoneal sarcomas: multivariate analysis of surgical factors associated with local control. J Clin Oncol 2009;27 (1):31-7.

[24] Gronchi A, Lo Vullo S, Fiore M, et al. Aggressive surgical policies in a retrospectively reviewed single-institution case series of retroperitoneal soft tissue sarcoma patients. J Clin Oncol 2009;27 (1):24-30.

[25] Li S. Primary retroperitoneal tumours. Zhonghua Wai Ke Za Zhi [Chinese Journal of Surgery] 1992;30 (11):648-50, 698 